УДК 502/504:628.54:502

ОЦЕНКА ВОЗДЕЙСТВИЯ СТРОИТЕЛЬСТВА ЛИНИИ ЖЕЛЕЗНОЙ ДОРОГИ НА ОКРУЖАЮЩУЮ СРЕДУ

Цыганков Д.А., Пирумова И.В., Воронцова Ю.В., Звягина Е.А.

ФГБОУ ВО «Сибирский государственный университет путей сообщения», Новосибирск, е-mail: palsatan@outlook.com

Статья представляет собой работу по оценке воздействия строительства внутренней железнодорожной линии промышленного предприятия длиной 566 м на воздушную и водную среду, земельные ресурсы (почвы), а также недра. При этом уделяется большое внимание образующимся отходам производства и потребления природных ресурсов, воздействию на растительный и животный мир, а также рассмотрению экономического ущерба от загрязнения окружающей среды. В результате проведения работы выяснилось, что большая часть загрязнения воздушной среды происходит за счёт проведения земляных работ по планированию территории застройки и пересыпке грунтов. Согласно принятым решениям, использование водных ресурсов главным образом носит безвозвратный характер, проявляющийся в их применении для производственных и хозяйственно-бытовых нужд персонала. По результатам проведённых исследований нарушение плодородного слоя почвы носит весьма ограниченный характер, а сам он срезается и перемещается на рекультивируемые территории. Одним из значимых решений проведённой работы является передача образующихся токсичных отходов производства и потребления сторонним организациям для последующего складирования, захоронения или утилизации вне территории строительства. Ввиду малой площади, охватываемой строительством, воздействие рассматриваемой производственной деятельности на растительный и животный мир рассматривается как допустимое. Наряду с этим в работе предусматривается возможность возникновения и меры по профилактике возникновения аварийных ситуаций на период производства работ. По результатам проделанной работы главным веществом, загрязняющим воздушную среду, являются взвешенные частицы и неорганическая пыль с содержанием $\mathrm{SiO}_{2} 20-70 \%$, которые формируют 84,7\% суммы платежа за загрязнение воздушной среды. При этом из твёрдых отходов, утилизируемых вне территории строительства, 90,4\% приходится на строительный мусор.

Ключевые слова: оценка воздействия, окружающая среда, железнодорожная линия, воздушная среда, водная среда, земельная среда, отходы, экономический ущерб

\title{
ENVIRONMENTAL IMPACT ASSESSMENT OF RAILWAY LINE CONSTRUCTION
}

Tsygankov D.A., Pirumova I.V., Vorontsova Yu.V., Zvyagina E.A.

Siberian Transport University, Novosibirsk,e-mail:palsatan@outlook.com

\begin{abstract}
The article is a work on assessing the impact of the construction of an internal railway line of an industrial enterprise with a length of 566 meters on the air, water environment, land resources (soils) and subsoil. At the same time, much attention is paid to production of consumption waste, the impact on flora and fauna, as well as consideration of economic damage from environmental pollution. As a result of the work, it turned out that most of the air pollution occurs due to excavation work to plan the development area and transfer soils. According to the decisions made in the work, the use of water resources is overwhelmingly irrevocable, manifested in their use for the production and household needs of the personnel. According to the results of the studies carried out, the disturbance of the natural soil layer is very limited, and it itself moves to reclaimed territories. One of the significant decisions of the work carried out is the transfer of the generated toxic production and consumption waste to thirdparty organizations for subsequent storage, utilization and disposal outside the construction side. Due to the small area covered by construction, the impact of the considered production activity of flora and fauna are considered acceptable. As the result of this, the work considers the possibility of occurrence and measures to prevent the occurrence of emergencies during the period of work. According to the results of the work done, the main substance that pollute the air are suspended particles and inorganic dust with a $\mathrm{SiO} 20-70 \%$ content, which form $84.7 \%$ of the amount of payment for air pollution. At the same time, of the solid waste disposed of outside the construction side, $90.4 \%$ falls on construction waste.
\end{abstract}

Keywords: impact assessment, environment, railway line, air environment, water environment, land environment, waste, economic damage

Охрана окружающей природной среды является одной из основных проблем общества, в основную задачу которой входит предотвращение негативных экологических последствий хозяйственной деятельности человека. Работа промышленных предприятий приводит к увеличению выбросов токсичных веществ в окружающую среду, которые могут привести к серьёзным последствиям. Одним из мероприятий, на- правленных на профилактику негативного воздействия производств на природу прилегающих территорий, является проведение процедуры оценки воздействия на окружающую среду, которая может быть не только важной социальной задачей, но и серьёзным фактором повышения эффективности общественного производства. Предельно допустимый выброс вредных веществ в атмосферу устанавливается для каждого 
источника загрязнения отдельно при условии, что суммарные выбросы вредных веществ, поступающие от него и источников населённого пункта с учётом перспективы развития предприятия и рассеивания вредных веществ в атмосфере, не создадут приземную концентрацию, превышающую их предельно допустимые концентрации для населения, растительного и животного мира. Дополнительный результат работы по оценке воздействия на окружающую среду - установление нормативов предельно допустимых воздействий на водную среду, земли (почвы) и недра. Отдельным пунктом выступает анализ процесса накопления и поведения отходов производства продукции и потребления необходимых для этого природных ресурсов.

Оценка воздействия объектов железнодорожного транспорта на окружающую среду является обязательным элементом планирования, проектирования и развития отрасли [1].

Целью исследования является создание условий для экологически безопасного строительства внутренней железнодорожной линии промышленного предприятия.

\section{Материалы и методы исследования}

Научное исследование осуществлено на базе результатов анализа фактического состояния окружающей природной среды, а также использования данных об объёмах проводимых строительно-монтажных работ и их оценки с применением стандартизованных методик.

\section{Результаты исследования и их обсуждение}

Климат района строительства - резко континентальный. Для него характерно короткое и жаркое лето, сменяющееся длинной и холодной зимой. Наиболее холодным месяцем года является январь, а жарким июль. Средняя температура воздуха января составляет $-14^{\circ} \mathrm{C}$, а июля $-+26,8^{\circ} \mathrm{C}$. Продолжительность периода с температурой воздуха не выше $0{ }^{\circ} \mathrm{C}-161$ сутки. Средняя относительная влажность воздуха в январе составляет 74,2\%, а в июле $-43,0 \%$. В январе преобладают юго-западные ветры со средней скоростью $3,8 \mathrm{M} / \mathrm{c}$, а в июле северо-восточные со средней скоростью 2,2 $\mathrm{M} / \mathrm{c}[2]$.

Объектом исследования является площадка строительства железнодорожной ветки, имеющей выход на грузовой фронт погрузочно-разгрузочного пути. Строя- щийся путь для предприятия определён как внутренний и состоит из соединительной и погрузочно-разгрузочных частей. На нём расположен фронт грузовых операций в пределах линейного грузового фронта. Земляное полотно проектируемого пути на всём протяжении представлено насыпью типовой конструкции высотой до 6 м. Перед началом отсыпки земляного полотна производится срезка почвенно-растительного слоя толщиной 20 см по всей длине трассы проектируемого железнодорожного пути. На грузовом фронте проектируемого пути предусматривается погрузка-выгрузка стальных и полиэтиленовых труб, выгрузка мешков с гранулами полиэтилена и прочих грузов на специально оборудованной для этого грузовой площадке с твёрдым водонепроницаемым покрытием. Строящаяся железнодорожная линия принадлежит предприятию «Темир-Сервис Астана». Подача, уборка, расстановка вагонов, а также техническое обслуживание пути осуществляется манёвровыми бригадами предприятия «Астанинское железнодорожное хозяйство» (рисунок).

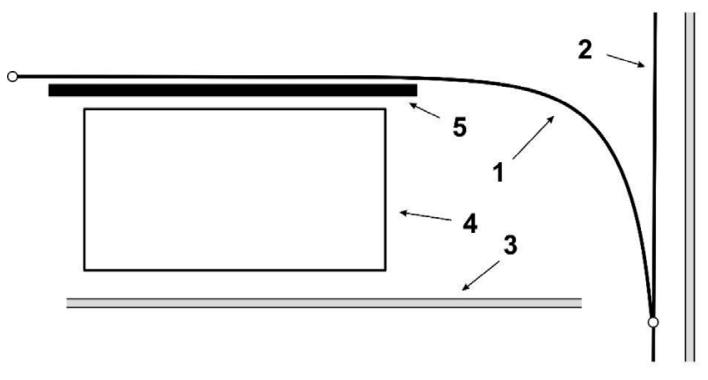

Внутренние железнодорожные пути производственного объекта: 1 - строящаяся железнодорожная ветка; 2 - существующая железнодорожная ветка; 3 - внутренняя автодорога; 4 - производственное здание;

5 - погрузочно-разгрузочная площадка

Основные объёмы и сроки проведения работ указаны в табл. 1 .

Загрязнение воздушной среды в период проведения строительно-монтажных работ прежде всего обусловлено приведением земляных работ, которые включают в себя снятие, погрузку, трансформирование плодородного слоя почвы и отсыпку железнодорожного полотна щебнем. Предусматривается разработка грунта с общим объёмом выемки 8360,4 м³ , который используют для планирования территории и обратной за- 
сыпки траншей. Для проведения этих работ необходимо вывезти плодородный слой грунта в количестве $3593,4 \mathrm{~m}^{3}$ с объёмом временного хранения 579,6 м м $^{3}$ Основным загрязнителем атмосферы при проведении этих производственных процессов является неорганическая пыль с содержанием $\mathrm{SiO}_{2}$ 20-70\%. Показатели, характеризующие её выделение, представлены в табл. 2, а их расчёты проведены по методике [3].

Согласно [4] указанные в табл. 2 интенсивности выбросов токсичной пыли с содержанием $\mathrm{SiO}_{2} 20-70 \%$ не будут формировать опасные концентрации этого загрязнителя в атмосфере прилегающих территорий.

Поскольку на период строительства к работе будет привлечено 85 чел., то общий расход питьевой воды за это время составит $242,0 \mathrm{M}^{3}$, а водоотведение - 169,4 м³ $^{3}$ Техни- ческая вода на время строительства будет доставляться из соответствующего источника, а её расход составит 2761,9 м ${ }^{3}$ (табл. 3).

В связи с тем, что в зоне расположения объекта строительства отсутствуют поверхностные водные объекты, мероприятия по защите водной среды не предусматриваются.

В качестве мероприятий по сохранению земель в работе предусматривается снятие плодородного слоя почвы с нарушаемой поверхности и его перемещение на рекультивируемые участки, находящиеся вне пределов производственной территории.

По результатам геологоразведочных работ в районе строительства не обнаружены запасы полезных ископаемых. В этой связи в работе не предусматриваются мероприятия по охране недр.

Таблица 1

Базовые технико-экономические показатели строительства железнодорожного пути

\begin{tabular}{|c|l|c|c|}
\hline № & \multicolumn{1}{|c|}{ Наименование показателей } & Единицы измерения & Количество \\
\hline 1 & Укладка пути & м & 566,0 \\
\hline 2 & Земляные работы & м $^{3}$ & 2732,0 \\
\hline 3 & Срок строительства & мес. & 3,4 \\
\hline 4 & Период строительства & \multicolumn{2}{|c|}{ май - август 2021 г. } \\
\hline
\end{tabular}

Таблица 2

Расчёт объёмов выделяемой пыли, содержащей $\mathrm{SiO}_{2} 20-70 \%$ при ведении земляных работ

\begin{tabular}{|c|c|c|c|}
\hline № & Наименование производственного процесса & Единицы измерения & Количество \\
\hline \multirow[t]{2}{*}{1} & \multirow{2}{*}{ Снятие и погрузка плодородного слоя } & $\Gamma / \mathrm{c}$ & 0,017 \\
\hline & & т/период & 0,0073 \\
\hline \multirow[t]{2}{*}{2} & \multirow{2}{*}{ Формирование плодородного слоя } & $\Gamma / \mathrm{c}$ & 0,0003 \\
\hline & & т/период & 0,00013 \\
\hline \multirow[t]{2}{*}{3} & \multirow{2}{*}{ Разгрузка щебня } & $\Gamma / \mathrm{c}$ & 0,032 \\
\hline & & т/период & 0,017 \\
\hline \multirow[t]{2}{*}{4} & \multirow{2}{*}{ Планирование железнодорожного полотна } & $\Gamma / \mathrm{c}$ & 0,0006 \\
\hline & & т/период & 0,0004 \\
\hline \multirow[t]{2}{*}{5} & \multirow{2}{*}{ Отсыпка железнодорожного полотна щебнем } & $\Gamma / \mathrm{c}$ & 0,03228 \\
\hline & & т/период & 0,01715 \\
\hline \multirow[t]{2}{*}{6} & \multirow{2}{*}{ Разгрузка грунта } & $\Gamma / \mathrm{c}$ & 0,033 \\
\hline & & т/период & 0,024 \\
\hline \multirow[t]{2}{*}{7} & \multirow{2}{*}{ Формирование железнодорожного полотна } & $\Gamma / \mathrm{c}$ & 0,00028 \\
\hline & & т/период & 0,00015 \\
\hline
\end{tabular}

Баланс водопотребления и водоотведения

Таблица 3

\begin{tabular}{|c|l|c|c|}
\hline № & \multicolumn{1}{|c|}{ Наименование показания } & Единицы измерения & Количество \\
\hline 1 & Потребление свежей воды на производственные нужды & $\mathrm{m}^{3} / \Gamma$ & 2761,9 \\
\hline 2 & Потребление свежей воды на хозяйственно-бытовые нужды & $\mathrm{m}^{3} / \Gamma$ & 242,0 \\
\hline 3 & Водоотведение хозяйственно-бытовых нужд & $\mathrm{M}^{3} / \Gamma$ & 169,4 \\
\hline
\end{tabular}


Таблица 4

Образование отходов производства и потребления на период строительства

\begin{tabular}{|c|l|c|c|}
\hline № & \multicolumn{1}{|c|}{ Наименование показателя } & Единицы измерения & Количество \\
\hline 1 & Строительный мусор и ТБО & т/ч & 10,1 \\
\hline 2 & Тара из-под лакокрасочных материалов & т/ч & 0,6 \\
\hline 3 & Ветошь промасленная & т/ч & 0,5 \\
\hline 4 & Огарки электродов & $\mathrm{T} / \mathrm{Y}$ & 0,02 \\
\hline
\end{tabular}

Таблица 5

Размеры платежей за нормативные выбросы в атмосферу в течение периода строительства

\begin{tabular}{|c|l|c|c|c|}
\hline № & \multicolumn{1}{|c|}{$\begin{array}{c}\text { Наименование } \\
\text { загрязняющего вещества }\end{array}$} & $\begin{array}{c}\text { Плата за 1 т, } \\
\text { руб. }\end{array}$ & $\begin{array}{c}\text { Количество, } \\
\text { т }\end{array}$ & $\begin{array}{c}\text { Сумма платы, } \\
\text { руб. }\end{array}$ \\
\hline 1 & Железа оксид & 2,5 & 0,047 & 475,27 \\
\hline 2 & Марганец и его соединения & 0,8 & 0,003 & 8,55 \\
\hline 3 & Взвешенные частицы & 0,8 & 1,021 & 3312,08 \\
\hline 4 & Азота диоксид & 1,7 & 0,076 & 521,97 \\
\hline 5 & Пыль неорганическая $\mathrm{SiO}_{2} 20-70 \%$ & 0,8 & 1,314 & 4262,83 \\
\hline 6 & Свинец и его соединения & 332,2 & 0,00006 & 86,23 \\
\hline 7 & Пыль древесная & 0,8 & 0,022 & 71,12 \\
\hline 8 & Прочие & 0,03 & 1,702 & 207,17 \\
\hline
\end{tabular}

Пр и м ечан и е. Сумма платы рассчитана с учётом максимальной разовой платы и местного повышающего коэффициента.

Согласно анализу технологии строительства железнодорожного пути в период строительства объекта будут формироваться следующие виды отходов: строительный мусор; тара из-под лакокрасочных материалов; твёрдые бытовые отходы; промасленная ветошь; огарки электродов. Все они передаются сторонним организациям для складирования, захоронения или утилизации (табл. 4).

Расчёт платы за загрязнение воздуха проведён согласно методике [5], а результаты представлены в табл. 5.

В качестве мероприятий по сохранению качества воздушной среды предусматриваются: выполнение земляных работ с пылеподавлением; приёмка строительных материалов без их хранения на территории производства работ; использование отходов в собственном строительном производстве или их передача на утилизацию сторонним организациям; укрытие автомобилей, перевозящих пылящие грузы, тентами.

Для снижения общего уровня загрязнения воздуха и экономии технической воды при проведении работ предусматривается: доставка грузов автосамосвалами с плотно закрытыми бортами; отсутствие заправки автотранспорта в пределах строительной площадки; обработка поверхностей, подверженных коррозии, битумом; использование биотуалетов.
Под регулированием выбросов загрязняющих веществ в атмосферу понимается их кратковременное сокращение в периоды неблагоприятных метеорологических условий (НМУ): сильных инверсий температуры воздуха, штилей, туманов, пыльных бурь, влекущих за собой резкое увеличение загрязнения атмосферы.

Для НМУ на участке строительно-монтажных работ предусматриваются:

1. Снижение производительности отдельных аппаратов и технологических линий, работа которых связана со значительным выделением в атмосферу вредных веществ.

2. Прекращение работы оборудования, если сроки начала планово-предупредительных работ по ремонту технологического оборудования и наступления НМУ достаточно близки.

3. Уменьшение интенсивности технологических процессов, связанных с повышенными выбросами вредных веществ в атмосферу на тех предприятиях, где за счёт интенсификации и использования более качественного сырья возможна компенсация отставания в периоды НМУ.

4. Отключение аппаратов и оборудования, работа которых связана со значительным загрязнением воздуха.

5. Временное прекращение погрузочноразгрузочных работ, а также отгрузки гото- 
вой продукции, сыпучего сырья и реагентов, являющихся источниками загрязнения.

6. Перераспределение нагрузки производств и технологических линий на более эффективное оборудование.

7. Остановка пусковых работ на аппаратах и технологических линиях, сопровождающихся выбросами в атмосферу.

8. Запрет выезда на линии автотранспортных средств с неотрегулированными двигателями.

Первым мероприятием по охране поверхности территории застройки предусмотрено рациональное расположение зданий, объектов строительства и временных сооружений с учётом требований рационального использования земельных ресурсов, а вторым - частичная засыпка котлованов с использованием вынутых грунтов.

Проектируемый объект расположен на урбанизированной территории, подвергнутой антропогенному воздействию. Эта территория не является местом обитания краснокнижных видов животных и растений. На прилегающей площади отсутствуют особо охраняемые природные территории, а также исторические и археологические памятники. При проведении строительных работ снос зелёных насаждений не предусматривается в связи с их отсутствием. Воздействие на растительный и животный мир при реализации проекта на период строительства оценивается как допустимое.

Основными причинами возможных аварийных ситуаций являются технологические, механические и организационно-технологические отказы, а также чрезвычайные ситуации. Это может являться следствием нарушения технологии производства работ, полного или частичного разрушения машин и механизмов, а также пожаров и взрывов. Поэтому в работе предусматривается периодическое проведение всех видов инструктажей, контроль наличия средств индивидуальной защиты работников и умения ими пользоваться, своевременное устранение утечек горюче-слезоточивых материалов, а также использование металлической тары для сбора отработанных масел.

\section{Заключение}

В данной работе была выполнена качественная и количественная оценка воздействия строительства внутренней железнодорожной ветки предприятия «Темир-Сервис Астана» на окружающую природную среду с выявлением источников негативного воздействия, а также проведена комплексная оценка состояния затрагиваемых работами природных объектов и сред.

На основании результатов проделанной работы можно сделать следующие выводы:

1. В результате проведённой оценки воздействия комплекса строительно-монтажных работ на окружающую воздушную среду выяснилось, что её наибольшее загрязнение происходит вследствие выбросов взвешенных частиц и неорганической пыли с содержанием $\mathrm{SiO}_{2} 20-70 \%$. В этой связи $84,7 \%$ общей суммы платежа за нанесение ущерба воздушной среде обусловлено выбросами этих двух видов загрязнений.

2. Несмотря на высокий объём безвозвратного водопотребления, составляющий $94,4 \%$, ввиду его общего небольшого количества загрязнение поверхностных и подземных водных объектов не происходит.

3. Воздействие на почвенный покров земли оценивается как незначительное.

4. Вследствие заключения хозяйственных договоров по передаче образующихся отходов производства и потребления природных ресурсов сторонним организациям, их действие не оказывает влияния на окружающую природную среду в пределах территории строительства. При этом 90,4\% образующихся отходов производства приходится на строительный мусор.

5. Воздействие объекта строительства на растительный и животный мир оценивается как допустимое.

\section{Список литературы / References}

1. Экологическая стратегия ОАО «Российские железные дороги» на период до 2017 года и на перспективу до 2030 года. Утверждена распоряжением ОАО «РЖД» от 12 мая 2014 года № 1143 p. [Электронный ресурc]. URL: http://www.rzd-expo. ru/innovation/regulatory documents/07 293r.pdf (дата обращения: 17.12.2021).

Environmental strategy of JSC Russian Railways for the period up to 2017 and for the future until 2030. Approved by the order of JSC Russian Railways dated May 12, 2014 No. 1143 r. [Electronic resource]. URL: http://www.rzd-expo.ru/ innovation/regulatory_documents/07_293r.pdf (date accessed: 17.12.2021) (in Russian).

2. СПРК 2.04-01-2017. Строительная климатология. Свод правил республики Казахстан. [Электронный ресурс]. URL: https://azimut-geology.kz/library/inzh_geo/100sp-rk-204-01-2017-stroitelnaya-klimatologiya.html (дата обращения: 17.12.2021).

SPRK 2.04-01-2017. Construction climatology. The set of rules of the Republic of Kazakhstan. [Electronic resource]. URL: https://azimut-geology.kz/library/inzh geo/100-sp-rk204-01-2017-stroitelnaya-klimatologiya.html (date accessed: 17.12.2021) (in Russian).

3. Методика расчёта выбросов загрязняющих веществ в атмосферу. К приказу министра охраны окружающей среды республики Казахстан от 18.04.2018 № 100-П. [Электронный ресурс]. URL: https://adilet.zan.kz/rus/docs/ V14M0009585 (дата обращения: 17.12.2021).

Methodology for calculating emissions of pollutants into the atmosphere. By order of the Minister of Environ- 
mental Protection of the Republic of Kazakhstan dated 04/18/2018 No. 100-P. [Electronic resource]. URL: https:/ adilet.zan.kz/rus/docs/V14M0009585 (date of access: 17.12.2021) (in Russian).

4. Методика расчёта нормативов выбросов от неорганизованных источников. Приложение № 13 к приказу министра охраны окружающей среды республики Казахстан от 18.04.2018 № 100-П. [Электронный ресурс]. URL: https:// online.zakon.kz/Document/?doc id=30378563 (дата обращения: 17.12.2021).

Methodology for calculating emission standards from fugitive sources. Appendix No. 13 to the order of the Minister of Environmental Protection of the Republic of Kazakhstan dated
April 18, 2018 No. 100-P. [Electronic resource]. URL: https:// online.zakon.kz/Document/?doc id=30378563 (date of access: 17.12.2021) (in Russian).

5. Методика расчёта платы за эмиссию в окружающую среду. Приказ министра охраны окружающей среды республики Казахстан от 08.04.2019 № 68-П. [Электронный ресурс]. URL: https://adilet.zan.kz/rus/docs/V090005672 (дата обращения: 17.12.2021).

Methodology for calculating payments for emissions into the environment. Order of the Minister of Environmental Protection of the Republic of Kazakhstan dated 08.04.2019 No. 68-P. [Electronic resource]. URL: https://adilet.zan.kz/rus/docs/ V090005672_ (date of access: 17.12.2021) (in Russian). 